\title{
Exclusion of pregnancy in dialysis patients: diagnostic performance of human chorionic gonadotropin
}

\author{
Natalja Haninger-Vacariu ${ }^{1 *}$ (D), Harald Herkner ${ }^{2}$, Matthias Lorenz ${ }^{3}$, Marcus Säemann ${ }^{4,5}$, Andreas Vychytil ${ }^{1}$, \\ Martin Jansen ${ }^{6}$, Rodrig Marculescu ${ }^{7}$, Reinhard Kramar $^{8}$, Gere Sunder-Plassmann ${ }^{1}$ and Alice Schmidt ${ }^{1}$
}

\begin{abstract}
Background: A positive pregnancy test in acute or chronically ill patients has implications for the use of potentially mutagenic or teratogenic products in urgent medical therapies such as the use of chemotherapies or therapies with immunosuppressants, for anesthesia, and for time-sensitive indications like urgent surgery or organ Transplantation. Despite a lack of evidence, it is currently believed that human chorionic gonadotropin serum concentrations are always elevated in female dialysis patients even without pregnancy. It is also believed that human chorionic gonadotropin cannot be used to confirm or exclude pregnancy.
\end{abstract}

Methods: Human chorionic gonadotropin was examined in female dialysis patients (18-50 years of age), and was classified as positive above $5 \mathrm{mlU} / \mathrm{ml}$. In addition, fertility status was determined. For an enhanced index test, the cut-off of $5 \mathrm{mlU} / \mathrm{ml}$ was used for potentially fertile patients and $14 \mathrm{mlU} / \mathrm{ml}$ for infertile patients to calculate diagnostic test accuracy. The ideal cut-off for human chorionic gonadotropin was estimated using Liu's method with bootstrapped $95 \%$ confidence intervals. Predictors of human chorionic gonadotropin increase were analyzed using multivariable linear regression.

Results: Among 71 women, two (2.8\%) were pregnant, 46 (64.8\%) potentially fertile, and 23 (32.4\%) infertile. We observed human chorionic gonadotropin concentrations $>5 \mathrm{mlU} / \mathrm{ml}$ in 10 patients, which had a sensitivity of 100\% (95\% confidence interval: 100 to 100), a specificity of $86 \%$ (95\% confidence interval: 77 to 94), a positive predictive value of 17\% (95\% confidence interval: 8 to 25$)$ and a negative predictive value of $100 \%$ (95\% confidence interval: 100 to 100) for the diagnosis of pregnancy. Using a cut-off $>14 \mathrm{mlU} / \mathrm{ml}$ for infertile patients or the exclusion of infertile patients increased specificity to $93 \%$ or $98 \%$, respectively. The ideal cut-off was $25 \mathrm{mlU} / \mathrm{ml}$ (95\% confidence interval: 17 to 33). Pregnancy and potential fertility, but not age, were independent predictors of human chorionic gonadotropin.

Conclusion: Human chorionic gonadotropin is elevated $>5 \mathrm{mlU} / \mathrm{ml}$ in $14.5 \%$ of non-pregnant dialysis patients of childbearing age. In potentially fertile women, this cut-off can be used to exclude pregnancy. In case of an unknown fertility status, the ideal human chorionic gonadotropin cut-off was $25 \mathrm{mlU} / \mathrm{ml}$.

Keywords: Anesthesia, Chronic kidney disease, Diagnostic accuracy, Dialysis, Fertility, Menopause, Menstrual cycle, Human chorionic gonadotropin, Follicle stimulating hormone, Anti-Müllerian hormone, Immunosuppressant, Kidney transplantation, Pregnancy, Surgery

\footnotetext{
* Correspondence: natalja.haninger-vacariu@meduniwien.ac.at

${ }^{1}$ Division of Nephrology and Dialysis, Department of Medicine III, Medical

University of Vienna, Währingergürtel 18-20, 1090 Vienna, Austria

Full list of author information is available at the end of the article
}

(c) The Author(s). 2020 Open Access This article is distributed under the terms of the Creative Commons Attribution 4.0 International License (http://creativecommons.org/licenses/by/4.0/), which permits unrestricted use, distribution, and reproduction in any medium, provided you give appropriate credit to the original author(s) and the source, provide a link to the Creative Commons license, and indicate if changes were made. The Creative Commons Public Domain Dedication waiver (http://creativecommons.org/publicdomain/zero/1.0/) applies to the data made available in this article, unless otherwise stated. 


\section{Background}

Traditional teaching suggests that surgery and general anesthesia in pregnancy should be postponed until after delivery to avoid unnecessary risks to the fetus [1]. However, reluctance to operate during pregnancy might become a self-fulfilling prophecy in which delay of surgery contributes to adverse perinatal outcomes traditionally attributed to surgery itself [2].

In this context, it is important to mention that kidney transplantation in pregnant dialysis patients can be associated with poor fetal outcome [3]. Thus, physicians should rule out pregnancy in kidney transplant candidates of childbearing age, especially in case of mycophenolic acid (MPA) use during initial immunosuppression. Although MPA significantly reduces incidence of acute rejection in general, MPA use in pregnancy is associated with an increased risk of miscarriage and congenital defects [4]. Therefore, the Food and Drug Administration mandates pregnancy testing immediately before and eight days following initiation of immunosuppressive therapy with MPA as part of a risk evaluation and mitigation strategy [4].

The diagnosis or exclusion of early pregnancy among dialysis patients is thought to be demanding because it is generally believed that human chorionic gonadotropin (hCG) serum concentrations can be elevated in dialysis patients even without pregnancy [5]. However, during the last four decades only three case reports and four small case series described 11 post-menopausal dialysis patients and nine dialysis patients of reproductive age showing elevated hCG serum concentrations in a range suggestive of gestational weeks 3 to 5 [6-12]. Despite these results, dialysis patients were neither pregnant nor presented with malignancy. In addition to hCG testing, transvaginal ultrasonography represents a useful tool for pregnancy investigation. Although, transvaginal ultrasonography can only identify a gestational sac at 5 weeks of gestational age with a diameter $>5 \mathrm{~mm}$ [13]. Thus, anesthesiologists and transplant practitioners are faced with a diagnostic window of several weeks when pregnancy in dialysis patients or kidney transplant candidates with elevated hCG serum concentrations cannot safely be excluded.

We aimed to examine the diagnostic performance of hCG serum concentrations for the exclusion or diagnosis of pregnancy in an Austrian sample of female dialysis patients less than 50 years of age. The results may inform decisions on diagnostic thresholds and use of pregnancy testing in this patient population.

\section{Methods}

Between May 2016 and December 2017, consecutive female dialysis patients of childbearing age (defined as 18 to 50 years of age) from four dialysis units in Vienna,
Austria (Dialysis Centre Vienna, Hospital St. John of God, Medical University of Vienna, Wilhelminenspital) were prospectively included in this study.

Eligible patients were identified using the Austrian Dialysis and Transplant Registry, which has provided nearly $100 \%$ coverage of patients on chronic renal replacement therapies in Austria since 1965. Patient history and clinical data including current pregnancies were obtained by baseline and follow-up interviews, and chart review.

The institutional review boards (IRB) of all four participating centers approved the study (unique IRB identifier for Medical University of Vienna: 750/2016; Dialysis Centre Vienna and Hospital St. John of God: 27-2-17; Wilhelminenspital: EK 17-058-VK). All participants gave written informed consent. Investigations were in accordance with the Declaration of Helsinki.

Blood samples were collected before dialysis and serum concentrations of hCG, follicle stimulating hormone (FSH), luteinizing hormone (LH), and anti-Müllerian hormone $(\mathrm{AMH})$ were measured using the Roche $\operatorname{cobas}^{\oplus} 8000$ modular analyzer, immunoassay module (e 602, Roche Diagnostics International Ltd., Rotkreuz, Switzerland) by electrochemiluminescence immunoassay (ECLIA). At first, the AMH Gen II ELISAC 2015 (Beckman Coulter, Inc. 250 S. Kraemer Blvd., Brea, CA 92821 U.S.A.), an enzymatically amplified two-site immunoassay, was used for measurement of AMH.

Reference intervals provided by the manufacturers of the laboratory tests were used to classify serum hormone concentrations as low, normal or elevated (Table S1). All analyses were performed in one International Organization for Standardization 15,189 accredited clinical laboratory of the Department of Laboratory Medicine at the Medical University of Vienna

The definition of true menopause in dialysis patients is not unequivocal because, in the absence of a menstrual cycle, women can regain fertility with hormone therapy, intensified dialysis and after transplantation [14]. We used the gynecological history (including menstrual cycle: yes, irregular, no; oophorectomy: yes or no) and hormonal profile to classify patients as pregnant, potentially fertile or infertile [14]. The potentially fertile patients included women with ovulatory or suspected functional anovulatory cycles representing patients without menopause or with functional menopause. The infertile women had pre- or true menopause. According to the Stages of Reproductive Aging Workshop (STRAW) criteria, an elevated FSH and low AMH concentration were used to ascertain infertility [15]. In dialysis patients, an elevation of $\mathrm{FSH}$ concentrations also indicates true menopause [14]. Serum AMH concentrations were found to be similar in dialysis patients and healthy controls $[16,17]$ and thus we used low AMH concentrations to ascertain infertility in selected cases. We also described LH serum concentrations, which are usually 
elevated in case of menopausal transition, infertility or in dialysis patients $[18,19]$.

Categorized data are presented as absolute count and relative frequency. Continuous data are presented as mean \pm standard deviation, if they are approximately normally distributed, or as a median value with $25-75 \%$ interquartile ranges. We used standard methodology to calculate summary statistics for diagnostic tests, including sensitivity, specificity, positive and negative predictive values with 95\% confidence intervals. The reference test was pregnancy, the index test was hCG. A cut-off of $5 \mathrm{mlU} / \mathrm{ml}$ was used to classify patients as positive for elevated levels of hCG [20]. For an enhanced index test, we classified hCG as positive above a cut off at $5 \mathrm{mlU} / \mathrm{ml}$ for potentially fertile patients and $14 \mathrm{mlU} / \mathrm{ml}$ for infertile patients [21]. A potential stratum effect of potential fertility on the summary statistics for diagnostic tests was investigated by use of stratification. In addition, the ideal cut-off for hCG was estimated using the Liu method, which maximizes the product of sensitivity and specificity in the ROC space [22]. The estimated cut-off value was determined with a bootstrapped $95 \%$ confidence interval.

Predictors of hCG increase were analyzed using multivariable linear regression. Human chorionic gonadotropin was the outcome on the log-transformed scale; age (years), pregnancy (yes versus no), and potential fertility (yes versus no) were used as covariables. MS Excel and Stata 14 for Mac were used for data management and analyses. In general, a two-tailed $p$-value less than 0.05 was considered statistically significant.

This study was conducted and the manuscript prepared according to the Standards for Reporting Diagnostic Accuracy (STARD) statement and the Quality Assessment of Diagnostic Accuracy Studies 2 (QUADAS-2) [23, 24].

\section{Results}

During the 19-month study period, 71 consecutive female dialysis patients aged 18-50 years were enrolled from four dialysis centers in Vienna. This study sample represents roughly $32 \%$ of the Austrian dialysis population of this sex and age category (point prevalence of dialysis patients $>18$ years of age in Austria as of December 31st 2016: 4584; point prevalence of female dialysis patients aged $18-50$ as of December 31st 2016: 221). The detailed assembly of the study cohort is given in Fig. 1. Overall rate of patient participation in the four study centers was about $96 \%$.

Among the 71 enrolled women, two (2.8\%) were pregnant, one did not know at the time of blood sampling and both presented with distinct elevated hCG serum concentrations; both pregnancies were recognized after

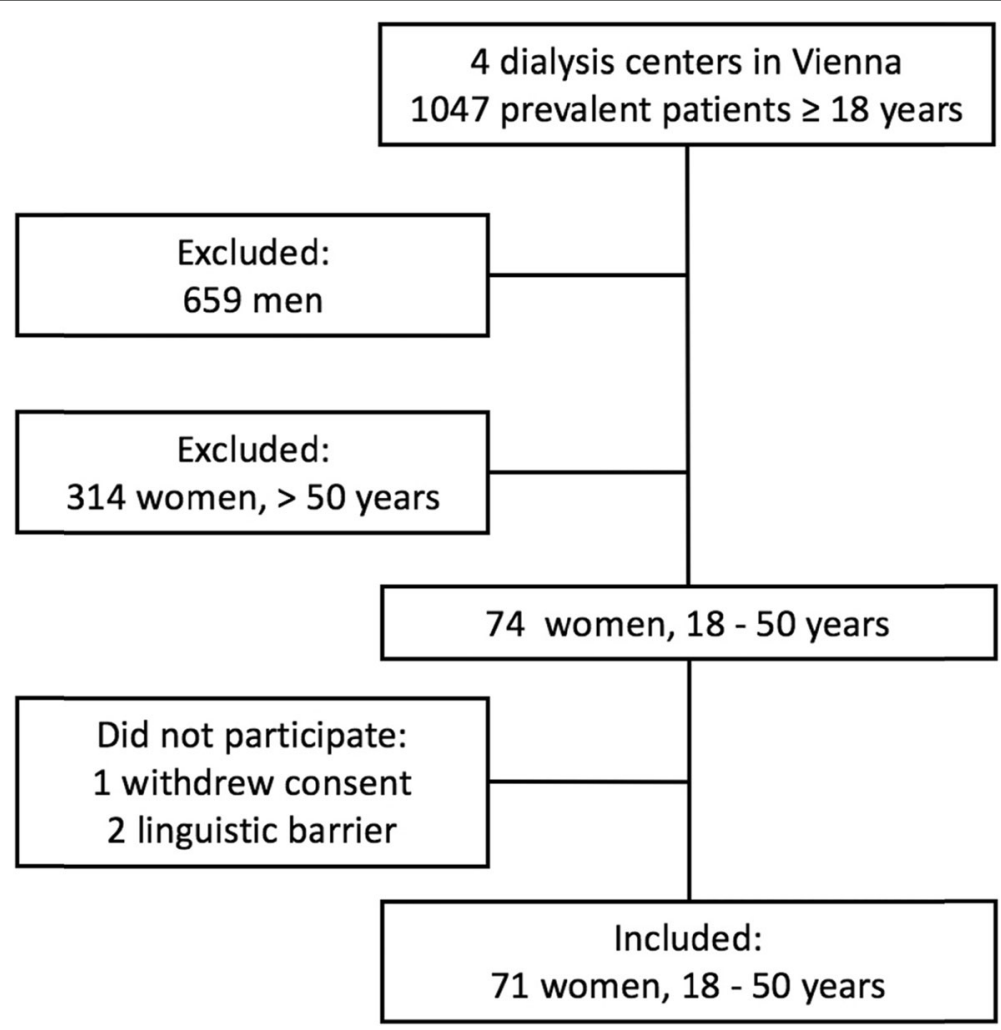

Fig. 1 Patient disposition 
initiation of the study. At the time of blood sampling for this study $34 \%$ of the patients were waitlisted for kidney transplantation with a Eurotransplant waitlist status "transplantable" and 17\% with a Eurotransplant waitlist status "not transplantable". Demographic data, information on primary kidney disease and end-stage renal disease vintage of the entire study cohort is given in Table 1. Table 2 depicts the gynecological and obstetric history of all patients. 46 women were classified as potentially fertile and 23 as infertile (Table 3). The median serum concentrations of hCG, LH, FSH, and AMH of 69 non-pregnant women and of menstrual cycle and menopausal status subgroups are indicated in Table 4. 25 cases presented with an undetectable serum hCG of $<$ $0.1 \mathrm{mlU} / \mathrm{ml}, 34$ cases with levels up to $5 \mathrm{mlU} / \mathrm{ml}$, and we observed concentrations $>5 \mathrm{mlU} / \mathrm{ml}$, potentially indicating pregnancy, in 10 patients $(14.5 \%$ of the nonpregnant cohort; Fig. 2). Follow-up, including personal interviews, excluded malignancies associated with elevated hCG concentrations, pregnancies or miscarriages in all 10 patients. Individual hCG serum concentrations according to pregnancy and fertility status are given in

Table 1 Demographic details of 71 female dialysis patients

\begin{tabular}{ll}
\hline Characteristics & $n=71$ \\
\hline Age, years & $43(32-47)$ \\
Age $\leq 40$ years & $30(42 \%)$ \\
Age, $40-50$ years & $41(58 \%)$ \\
BMl, kg/m² & $23.1(20.6-27.7)$ \\
Race, black, white, Asian & $1(1 \%) / 65(92 \%) / 5(7 \%)$ \\
Renal disease & \\
Diabetes & $4(6 \%)$ \\
Glomerulonephritis & $9(13 \%)$ \\
Secondary glomerulonephritis/ & $11(15 \%)$ \\
vasculitis & $7(10 \%)$ \\
Interstitial nephritis/pyelonephritis & $14(20 \%)$ \\
Cystic/hereditary/congenital diseases & $3(4 \%)$ \\
Neoplasms/tumors & $2(3 \%)$ \\
Complication after transplantation & $2(3 \%)$ \\
Miscellaneous conditions & $18(25 \%)$ \\
Unknown & $2.3(0.8-11.2)$ \\
Total ESRD vintage, years & $2.1(0.7-4.4)$ \\
Total dialysis time, years & \\
Number of patients with & $17(24 \%), 2(3 \%), 2(3 \%), 1$ \\
1, 2, 3, 4 previous kidney transplants & $(1 \%)$ \\
Duration of current dialysis, years & $1.6(0.4-2.9)$ \\
Current hemodialysis/peritoneal dialysis & $60(85 \%), 11(15 \%)$ \\
\hline Data expressd & \\
\hline
\end{tabular}

Data expressed either as median (IQR) for continuous variables or as count and percentage for categorical variables

$B M I$ body mass index, ESRD end-stage renal disease
Table 2 Gynecological and obstetric history of 71 female dialysis patients

\begin{tabular}{|c|c|}
\hline Characteristics & $n=71$ \\
\hline Age of menarche, years & $13(12-14)$ \\
\hline Total number of pregnancies ${ }^{a}$ & 147 \\
\hline Number of pregnancies per patient & $1(0-3)$ \\
\hline \multicolumn{2}{|l|}{ Number of patients with } \\
\hline $\begin{array}{l}\text { unknown, no, 1, 2, 3, 4, 5, 7, 10, } 11 \\
\text { pregnancies }^{\mathrm{a}}\end{array}$ & $1 / 28 / 8 / 8 / 10 / 3 / 6 / / 4 / 1 / 1$ \\
\hline Total number of live births & 90 \\
\hline Number of live births per patient & $1(0-2)$ \\
\hline \multicolumn{2}{|l|}{ Number of patients with } \\
\hline unknown, no, 1, 2, 3, 4, 5, 8 live births & $1 / 33 / 12 / 11 / 8 / 1 / 4 / 1$ \\
\hline $\begin{array}{l}\text { Current regular menstrual cycle } \\
\text { (including } 2 \text { pregnant women) }\end{array}$ & $31(44 \%)$ \\
\hline Current irregular menstrual cycle & $13(18 \%)$ \\
\hline Current amenorrhea & $25(35 \%)$ \\
\hline Current menstrual cycle unknown & $2(3 \%)$ \\
\hline No/functional/pre/true/unknown menopause & $36 / 11 / 8 / 15 / 1$ \\
\hline History of oophorectomy & $5(7 \%)$ \\
\hline Prior therapy with cyclophosphamide & $7(10 \%)$ \\
\hline Potentially fertile patients & $46(65 \%)$ \\
\hline
\end{tabular}

Data expressed either as median (IQR) for continuous variables or as count and percentage for categorical variables

${ }^{a}$ Two pregnancies during dialysis included in the present study, two other pregnancies during dialysis before the present study

Fig. 3. Table 5 shows demographic details and serum hormone concentrations of 12 women with hCG serum concentrations $>5 \mathrm{mlU} / \mathrm{ml}$, including two pregnant cases. One of the 10 non-pregnant women with an hCG serum concentration $>5 \mathrm{mlU} / \mathrm{ml}$ was considered potentially fertile, the other nine infertile. Clinical details, individual serum hormone concentrations and fertility status of 59 patients with hCG serum concentrations $\leq 5 \mathrm{mlU} /$ $\mathrm{ml}$ are indicated in Table S2.

An hCG serum concentration $>5 \mathrm{mlU} / \mathrm{ml}$ had a sensitivity of $100 \%$ (95\% CI: 100 to 100), specificity of $86 \%$ ( $95 \%$ CI: 77 to 94), positive predictive value of $17 \%$ (95\% CI: 8 to 25 ) and negative predictive value of $100 \%$ (95\% CI: 100 to 100) for the diagnosis of pregnancy. Using an hCG cut-off of $>14 \mathrm{mlU} / \mathrm{ml}$ for infertile patients, sensitivity and negative predictive value did not change, the specificity increased to $93 \%$ (95\% CI: 87 to 99 ) and positive predictive value was $29 \%$ (95\% CI: 18 to 39). Within the stratum of potentially fertile patients, specificity was 98\% (95\% CI: 94 to 100$)$ with a positive predictive value of $67 \%$ (95\% CI: 53 to 80). Sensitivity and negative predictive value remained unchanged. Cross tabulations of pregnancy as the reference standard and hCG as an index test are shown in Table S3. Overall, the ideal hCG 
Table 3 Patient categories, fertility status and menstrual cycle subgroups of 71 dialysis patients of reproductive age

\begin{tabular}{|c|c|c|c|}
\hline & $\begin{array}{l}\text { Potentially fertile }(n=46) \\
\text { No or functional menopause }\end{array}$ & $\begin{array}{l}\text { Infertile }(n=23) \\
\text { Pre- or true menopause }^{b}\end{array}$ & $\begin{array}{l}\text { Pregnant }(n=2) \\
\text { No menopause }^{c}\end{array}$ \\
\hline $\begin{array}{l}\text { Regular menstrual cycle } \\
(n=29)\end{array}$ & $\begin{array}{l}\text { Ovulatory or functional anovulatory cycle } \\
(n=24) \\
\text { (low AMH: } 3, \text { AMH unknown: } 1)\end{array}$ & $\begin{array}{l}\text { Based on history and/or elevated FSH }(n=5) \\
\text { (low AMH: 4) }\end{array}$ & $\begin{array}{l}\text { Regular menstrual cycle } \\
\text { before pregnancy }(n=2)\end{array}$ \\
\hline $\begin{array}{l}\text { Irregular menstrual cycle } \\
(n=13)\end{array}$ & $\begin{array}{l}\text { Ovulatory or functional anovulatory cycle } \\
(n=11) \\
\text { (low AMH: 1) }\end{array}$ & $\begin{array}{l}\text { Based on history and/or elevated FSH }(n=2) \\
\text { (low AMH: 2) }\end{array}$ & - \\
\hline Amenorrhea $(n=25)$ & $\begin{array}{l}\text { Functional menopause }(n=10) \\
\text { (low AMH: } 3 \text { ) }\end{array}$ & $\begin{array}{l}\text { Based on history and/or elevated FSH }(n=15) \\
\text { (low AMH: 12) }\end{array}$ & - \\
\hline $\begin{array}{l}\text { Unknown menstrual cycle } \\
(n=2)\end{array}$ & $\begin{array}{l}\text { Ovulatory or functional anovulatory cycle } \\
(n=1) \\
(\text { low } \mathrm{AMH}: 0)\end{array}$ & $\begin{array}{l}\text { Based on history and/or elevated FSH }(n=1) \\
\text { (low AMH: 1) }\end{array}$ & - \\
\hline
\end{tabular}

FSH follicle stimulating hormone, $A M H$ anti-Müllerian hormone

, low AMH: 7 of $46(15 \%) ;{ }^{\text {b }}$, low AMH: 19 of $23(83 \%) ;{ }^{c}$, low AMH: 0 of $2(0 \%)$

cut-off for our patient population was $25.0 \mathrm{mlU} / \mathrm{ml}(95 \%$ CI: 17 to 33$)$.

Pregnancy (coefficient: 8.7 (if pregnant); 95\% CI: 6.6 to 10.7; $p<0.001$ ) and potential fertility (coefficient: -2.7 (if potentially fertile); $95 \%$ CI: -3.5 to -1.8 ; $\mathrm{p}<0.001$ ) were independent predictors of hCG levels. In contrast, age had no effect on hCG serum concentrations (coefficient- 0.03 (per year of age); $95 \% \mathrm{CI}:-0.08$ to $0.01 ; p=0.13)$.

\section{Discussion}

We provide evidence that serum concentrations of hCG are elevated in only $2.2 \%$ of potentially fertile female dialysis patients of reproductive age, in contrast to $39 \%$ of infertile patients. This finding has implications for the exclusion of pregnancy in surgery settings and anesthesia in general, for time-sensitive indications such as deceased donor kidney transplantation, and for the use of MPA as a part of primary immunosuppression.

Fertility is diminished in dialysis patients with a pregnancy incidence between $<1-7 \%$ [5, 25-29]. Menopause occurs in these women 4.5 years earlier than in healthy women and primary ovarian failure, defined as a sign of menopause before the age of 40 years, is frequent with a proportion of $14 \%$ in comparison to $0.01 \%$ in the general population [30-32]. Profound endocrine abnormalities leading to menstrual and fertility disorders in dialysis patients are likely the result of a defect in hypothalamic regulation of gonadotropin secretion [33] and in the absence of other clinical correlates, serum concentrations of hCG may be elevated in these patients. When they do conceive, advanced renal failure predisposes them to abortion, intrauterine growth restriction and preterm delivery. Intensified dialysis may improve fertility and

Table 4 Serum hormone concentrations of non-pregnant dialysis patients and of subgroups according to menstrual cycle status and menopausal status

\begin{tabular}{|c|c|c|c|c|c|c|}
\hline \multirow[t]{3}{*}{ Hormone } & \multicolumn{4}{|c|}{ Serum concentration } & \multirow{2}{*}{\multicolumn{2}{|c|}{ Menopause $(n=69)$}} \\
\hline & \multirow[t]{2}{*}{ Non-pregnant } & \multicolumn{3}{|c|}{ Menstrual cycle $(n=67)^{a}$} & & \\
\hline & & Regular & Irregular & Amenorrhea & $\begin{array}{l}\text { No or } \\
\text { functional }\end{array}$ & Pre- or true \\
\hline (manufacturer and method) & $(n=69)$ & $(n=29)$ & $(n=13)$ & $(n=25)$ & $(n=46)$ & $(n=23)$ \\
\hline hCG (Roche, ECLIA), mlU/ml & $1.0(<0.1-2.0)$ & $1.0(0.1-1.0)$ & $0.1(0.1-1.0)$ & $1.0(0.5-6.0)$ & $0.1(0.1-1.0)$ & $4.0(1.5-7.45)$ \\
\hline LH (Roche, ECLIA), mlU/ml & $9.45(3.9-33.2)$ & $10.15(3.98-27.6)^{b}$ & $7.7(4.2-11.6)$ & $10.4(3.6-95.5)$ & $7.1(3.6-15.7)^{b}$ & $82.3(4.4-120.8)$ \\
\hline FSH (Roche, ECLIA), mIU/ml & $5.40(3.90-22.7)$ & $5.0(3.55-9.75)^{b}$ & $4.4(3.9-6.0)$ & $21.7(4.2-80.0)$ & $4.6(3.6-6.3)^{b}$ & $58.3(18.5-117)$ \\
\hline $\begin{array}{l}\text { AMH (Beckman-Coulter, } \\
\text { ELISA; } n=33), n g / m l\end{array}$ & $0.16(<0.08-3.2)$ & $0.66(0.1-3.44)$ & $4.2(0.86-6.3)$ & $0.08(<0.08-0.33)$ & $0.73(0.31-5.46)$ & $0.08(<0.08-<0.08)$ \\
\hline $\mathrm{n}$ & 33 & 14 & 6 & 12 & 21 & 12 \\
\hline $\begin{array}{l}\text { AMH (Roche, ECLIA; } n=35) \text {, } \\
\mathrm{ng} / \mathrm{ml}\end{array}$ & $0.19(0.01-0.8)^{b}$ & $0.36-(0.15-1.62)^{b}$ & $0.37(0.2-0.96)$ & $0.01(0.01-0.04)$ & $0.38(0.18-1.71)^{b}$ & $0.01(0.01-0.03)$ \\
\hline$n$ & $35^{\mathrm{b}}$ & $14^{\mathrm{b}}$ & 7 & 13 & $24^{b}$ & 11 \\
\hline
\end{tabular}

hCG human chorionic gonadotropin, $L H$ luteinizing hormone, FSH follicle stimulating hormone, $A M H$ anti-Müllerian hormone, ECLIA electrochemiluminescence immunoassay, ELISA enzyme linked immunosorbent assay

Data expressed as median (IQR); ${ }^{a}$ unknown menstrual cycle status in two patients; ${ }^{b} 1$ missing 


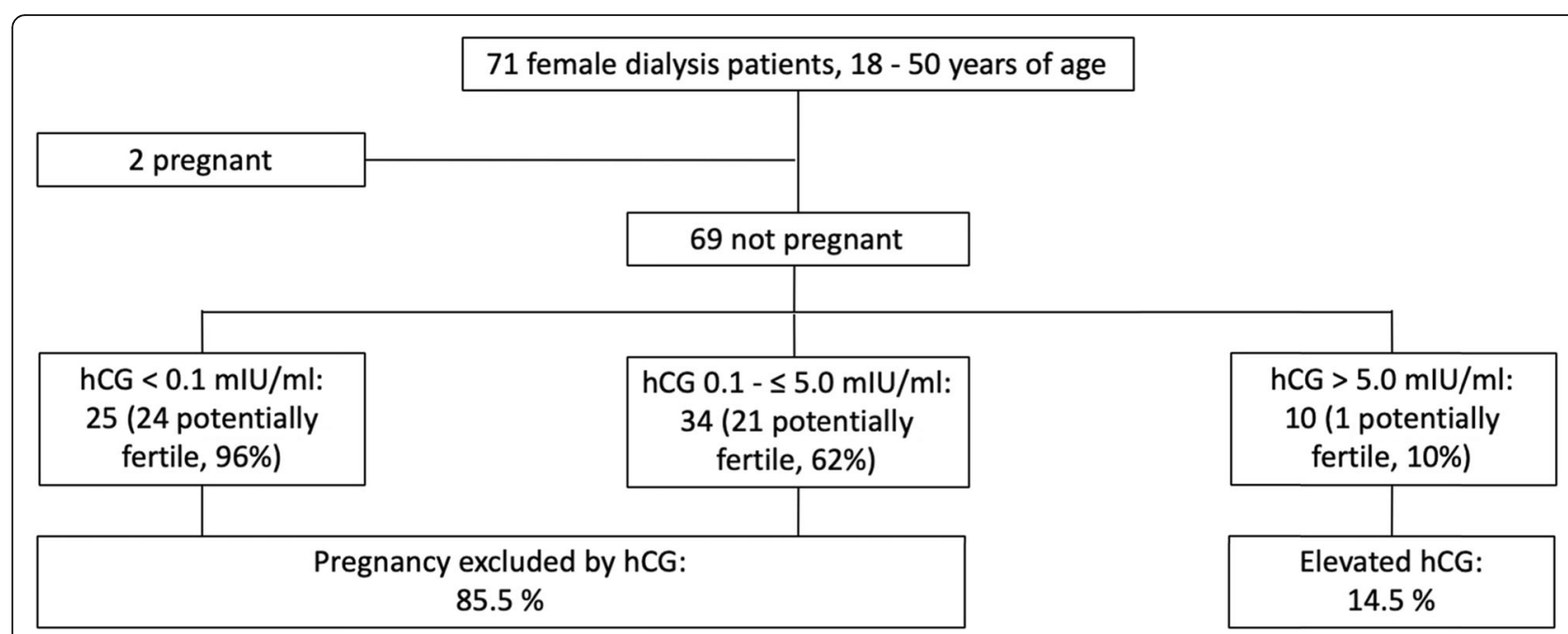

Fig. 2 Distribution of hCG serum concentrations among 71 female dialysis patients. The higher the hCG serum concentration, the lower the proportion of potentially fertile individuals in the different hCG serum concentration categories. hCG, human chorionic gonadotropin

pregnancy outcomes among dialysis patients, [34] but the rate of successful pregnancies is about four times greater after kidney transplantation (33/1000 female transplant recipients) but still less frequent as compared to the general population ( $>100 / 1000$ females) $[35,36]$. Notably, two studies showed an increase of the pregnancy rates among dialysis patients in recent years [37-39].

Tacrolimus and MPA are recommended as first line therapy for prevention of kidney allograft rejection [40]. However, MPA use in pregnancy is associated with an increased risk of miscarriage with a rate of $45-49 \%$ during the first trimester, and congenital defects, such as external ear malformation, cleft lip and palate, and abnormality of distal limbs, heart, esophagus or kidneys, which occur in $23-27 \%$ of cases. In comparison, the miscarriage rate in female solid organ recipients receiving other immunosuppression lies between 12 and 33\% and the rate of congenital defects between 4 and 5\%, which is comparable to $3 \%$ in the general US population [1]. Therefore, the FDA and EMA recommend pregnancy exclusion immediately before starting with MPA therapy, eight days later, and the use of contraceptives during ongoing therapy. Furthermore, the Report by the American Society of Anesthesiologists Task Force on Preanesthesia Evaluation suggested that pregnancy testing may be offered to female patients of childbearing age and for whom the result would alter the patient's management, because patients may present for anesthesia with early undetected pregnancy [41]. Surgery and anesthesia on a pregnant woman may have significant implications for the fetus and the mother, and it is commonly recommended that all surgery, unless truly emergent, be postponed until after delivery to minimize the risk to the fetus [2]. However, withholding indicated surgery from a pregnant woman as a result of fears of teratogenesis, pregnancy loss, or preterm birth would appear to be unfounded and may significantly contribute to both maternal and neonatal morbidity [3]. Taken together, an undetected pregnancy in a dialysis patient who undergoes kidney transplantation and uses MPA as part of the immunosuppressive therapy poses an unacceptable risk to the fetus [4].

Pregnancy can be diagnosed or excluded by measurement of hCG in urine or serum. It is a heterodimeric glycoprotein hormone composed of an alpha- and a specific beta-subunit. The hCG alpha-subunit is identical to the alpha-subunit of LH, FSH, and thyroid-stimulating hormone (THS) and before release into circulation, the alpha- and beta-subunits are non-covalently bound. $\mathrm{Hu}$ man chorionic gonadotropin is normally secreted by the syncytiotrophoblast of the placenta, but also by trophoblastic and gastrointestinal tumors. The main functions of hCG include the maintenance of progesterone secretion from the corpus luteum until the placenta takes over this function after 6 weeks of gestation; it also stimulates gonadal testosterone secretion of the male fetus. Very small amounts in men and women primarily derive from the anterior pituitary gland [42, 43]. Some $8 \%$ of menopausal women present with elevated serum concentrations of hCG of pituitary origin $>5 \mathrm{mlU} / \mathrm{ml}$ and a higher cut-off of $14 \mathrm{mlU} / \mathrm{ml}$ is recommended for women $>55$ years [21].

Today, serum hCG is measured by highly specific 2site immunometric assays using antibodies specific for the beta-subunit [20]. The urine hCG pregnancy tests detect the free beta-subunit and are less sensitive as compared to serum assays. In dialysis patients, urine tests are not recommended and not possible because of 


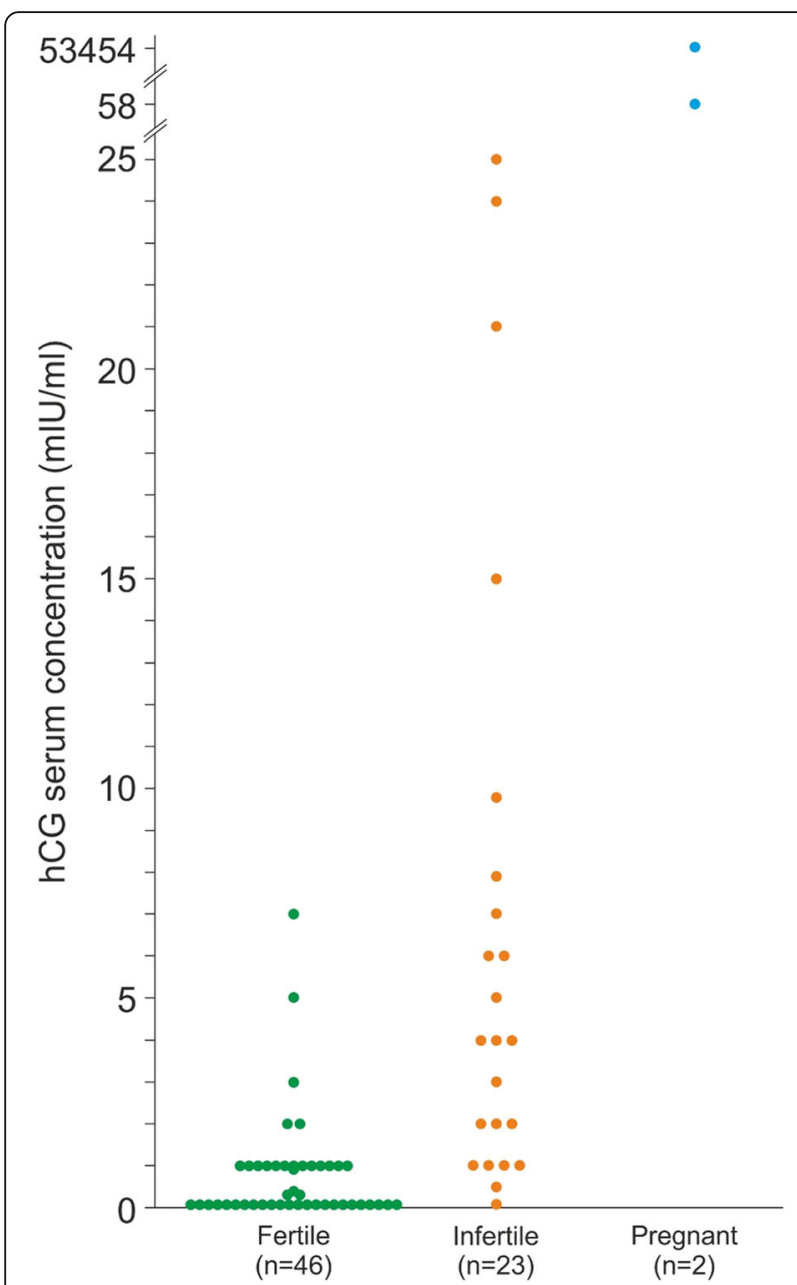

Fig. 3 Individual hCG serum concentrations of 71 potentially fertile, infertile, and pregnant dialysis patients. hCG, human chorionic gonadotropin

anuria, and serum hCG based pregnancy testing is reported to be unreliable due to a high rate of "false" positive results [9]. However, due to the lack of reliable data, this suggestion is only supported by a few case reports in the literature (summarized in Table S4).

Therefore, hCG serum concentrations were examined with a highly sensitive and specific test in female dialysis patients of reproductive age. Potential fertility and infertility were diagnosed with a detailed medical and gynecological history and measurement of serum concentrations of FSH, AMH and LH. Except for two pregnant patients, 46 out of 69 non-pregnant cases (67\%) were classified to be potentially fertile and 23 as infertile. Only one of the non-pregnant, potentially fertile women (2.2\%) presented with an hCG serum concentration $>5$ $\mathrm{mlU} / \mathrm{ml}$ (case 6 in Table 5). Nine further patients with elevated $\mathrm{hCG}>5 \mathrm{mlU} / \mathrm{ml}$ ( 6 to $25 \mathrm{mlU} / \mathrm{ml}$ ) were considered infertile, which represented $39 \%$ of the infertile patient group. Thus, among female dialysis patients of reproductive age, $14.5 \%$ presented with elevated serum hCG, and the vast majority of them were classified as infertile. In contrast to age, potential fertility and pregnancy were independent predictors of hCG serum concentrations.

In regard to diagnostic accuracy, this study showed that the hCG cut-off of $>5 \mathrm{mlU} / \mathrm{ml}$ had a specificity of $86 \%$ for the diagnosis of pregnancy among the group of female dialysis patients of childbearing age as a whole. Using a higher cut-off of $14 \mathrm{mlU} / \mathrm{ml}$ for the subgroup of infertile patients, specificity increased to $93 \%$. For the group of potentially fertile patients alone, specificity improved to $98 \%$. The positive predictive value increased accordingly in all three analyses, whereas sensitivity and the negative predictive value remained at $100 \%$. Thus, for potentially fertile dialysis patients of childbearing age a standard hCG serum concentration cut-off of $\leq 5 \mathrm{mlU} /$ $\mathrm{ml}$ can be used to safely exclude early pregnancy. In case of an unknown fertility status, the ideal cut-off for the diagnosis of pregnancy in our patient population was 25 $\mathrm{mlU} / \mathrm{ml}$, which corresponds well to the cut-off suggested by Braunstein et al. [20]. When a patient presents with an elevated hCG serum concentration, causes other than pregnancy or menopause should be considered. There may be malignancies or test interference with heterophilic antibodies, which are frequently encountered in patients with autoimmune diseases [44, 45].

Potential limitations to the study should also be considered, such as the small sample size which diminishes the generalizability of our data. Due to this, the wide confidence intervals reflect random sampling variability. However, given the importance of the outcome in light of the very low frequency of this condition, it appears to be a disproportionate effort to recruit more participants only to gradually increase precision before reporting this observation. Likewise, a confidence interval around the $100 \%$ predictive value is a result of no observations rather than a high precision. We cannot exclude the possibility of false negatives with a larger sample size. Moreover, by avoiding a case control study design, it was possible to exclude an important source of selection bias. Blinding of the index test was assured by the analysis of hCG in a department of laboratory medicine. There was no blinding of the reference standard, but we do not deem this a major source of bias for advanced pregnancy. However, this may not be the case for miscarriages. A stratum bias does not seem likely because patients were recruited from several institutions without traceable selection.

\section{Conclusion}

Our data show that highly specific serum hCG tests can be used in potentially fertile female dialysis patients to exclude pregnancy. While waitlisted for kidney transplantation or 


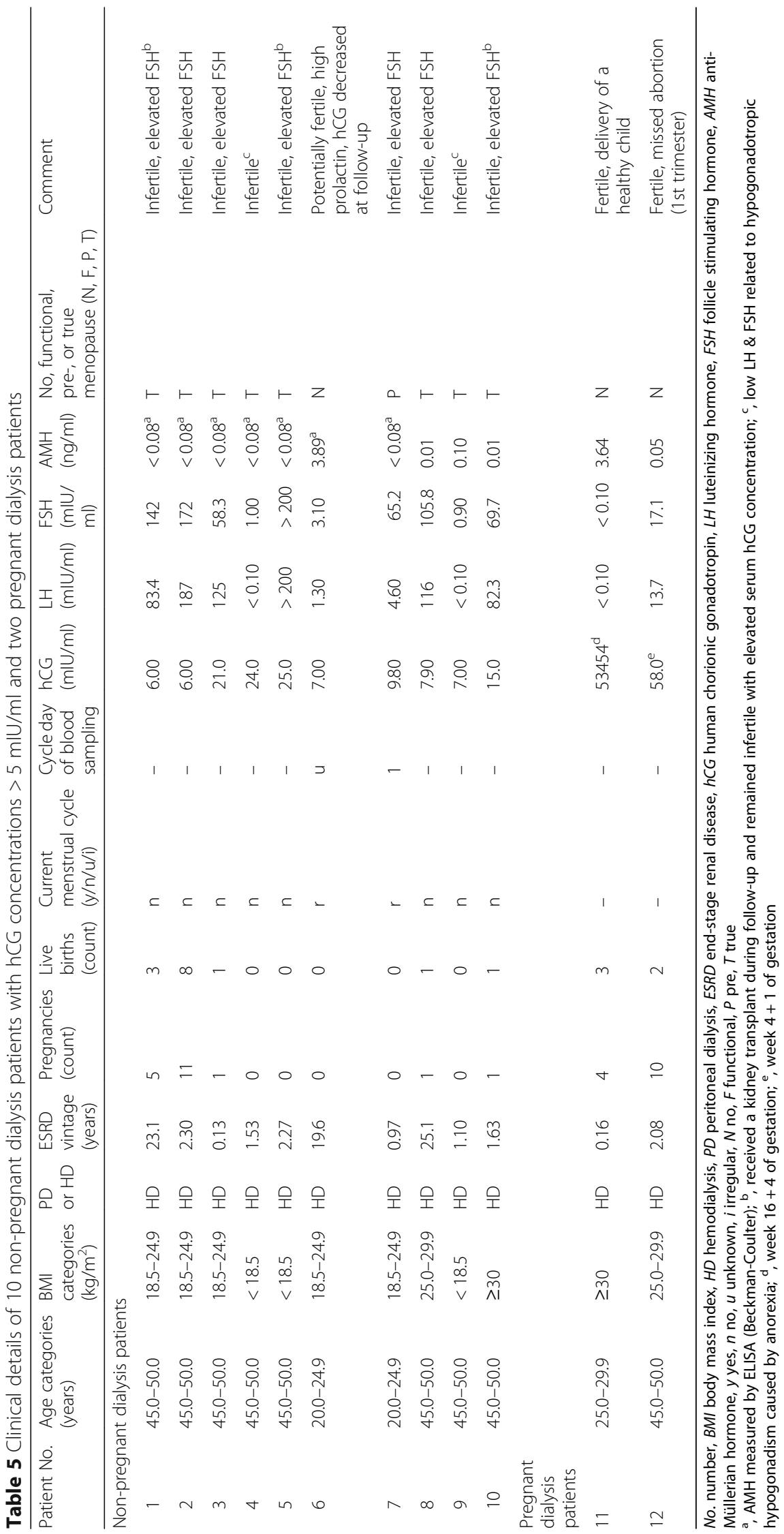


scheduled for elective surgery and anesthesia, an elevated hCG serum concentration in women of childbearing age should prompt an evaluation for the presence of functional, pre-, or true menopause, and include a gynecological history and determination of FSH and AMH serum concentrations.

In conclusion, the serum concentration of hCG was elevated $>5 \mathrm{mlU} / \mathrm{ml}$ in nearly half of infertile dialysis patients of childbearing age. In contrast, for potentially fertile women this cut-off can be used to exclude pregnancy. For the population as a whole, the ideal hCG cutoff was $25 \mathrm{mlU} / \mathrm{ml}$.

\section{Supplementary information}

Supplementary information accompanies this paper at https://doi.org/10. 1186/s12882-020-01729-5.

Additional file 1: Table S1. Reference intervals for hCG, FSH, LH, and AMH in females. Table S2. Clinical details of 59 female dialysis patients with $\mathrm{hCG}$ serum concentrations of $\leq 5 \mathrm{mlU} / \mathrm{ml}$. Table S3. Cross

tabulation of pregnancy as the reference standard and $\mathrm{hCG}$ as index test.

Table S4. Studies reporting elevated serum concentrations of hCG in 20 female dialysis patients.

\section{Abbreviations}

AMH: Anti-Müllerian hormone; ECLIA: Electrochemiluminescence immunoassay; FSH: Follicle stimulating hormone; hCG: Human chorionic gonadotropin; IRB: Institutional review boards; LH: Luteinizing hormone; MPA: Mycophenolic acid; QUADAS-2: Quality Assessment of Diagnostic Accuracy Studies 2; STARD: Standards for Reporting Diagnostic Accuracy; STRAW: Stages of Reproductive Aging Workshop; THS: Thyroid-stimulating hormone

\section{Acknowledgements}

We are grateful to the Department of Laboratory Medicine at the Medical University of Vienna for the determination of serum hormone concentrations, and to Leah Piggott for language editing of this manuscript, a student at Webster Vienna Private University.

\section{Prior presentation}

Part of this data was presented as a poster at the 56th Annual Meeting of the ERA-EDTA in Budapest, Hungary, in June 2019: "Pregnancy testing in dialysis patients: Diagnostic performance of human chorionic gonadotropin", by Natalja Haninger-Vacariu, Herkner Harald, Lorenz Matthias, Säemann Marcus, Vychytil Andreas, Jansen Martin, Marculescu Rodrig, Kramar Reinhard, SunderPlassmann Gere, and Schmidt Alice.

The conference abstract may be found at: https://academic.oup.com/ndt/ article/34/Supplement_1/gfz103.SP125/5515435

\section{Authors' contributions}

Study design: N.H.-V., H.H. and A.S.; identification of eligible patients and serum sample collection: N.H.-V., M.L., M.S., A.V., M.J. and R.K.; laboratory analyses: R.M.; participant recruitment: N.H.-V., M.L., A.V. and M.J.; completion of patient questionnaires: N.H.-V.; data analysis: H.H.; table and figure creation: G.S.P. and A.S.; data interpretation and drafting and revision of the manuscript: N.H.-V., H.H., G.S.P. and A.S.; all authors approved the final version of the manuscript and accept accountability for the overall work.

\section{Funding}

No funding was received for this study.

\section{Availability of data and materials}

All data generated or analyzed during this study are included in this published article [and its supplementary information files]. Furthermore, data are available from the corresponding author on reasonable request.

\section{Ethics approval and consent to participate}

The present study was approved by the local ethical review board (Medical University of Vienna - ECS 1750/2016). All participants gave written informed consent. Investigations were in accordance with the Declaration of Helsinki.

\section{Consent for publication}

Not applicable.

\section{Competing interests}

The authors declare that they have no competing interests.

\section{Author details}

${ }^{1}$ Division of Nephrology and Dialysis, Department of Medicine III, Medical University of Vienna, Währingergürtel 18-20, 1090 Vienna, Austria. ${ }^{2}$ Department of Emergency Medicine, Medical University of Vienna, 1090 Vienna, Austria. ${ }^{3}$ Dialysis Centre Vienna, 1220 Vienna, Austria. ${ }^{4}$ Department of Medicine VI, Wilhelminenspital, 1160 Vienna, Austria. ${ }^{5}$ Sigmund Freud Private University, Medical School, 1020 Vienna, Austria. ${ }^{6}$ Division of Gastroenterology and Nephrology, Department of Medicine I, Hospital St. John of God, 1020 Vienna, Austria. ${ }^{7}$ Department of Laboratory Medicine, Medical University of Vienna, 1090 Vienna, Austria. ${ }^{8}$ Austrian Dialysis and Transplant Registry, 4532 Rohr im Kremstal, Austria.

Received: 12 August 2019 Accepted: 19 February 2020

Published online: 28 February 2020

References

1. Maher JL, Mahabir RC. Preoperative pregnancy testing. Can J Plast Surg. 2012;20:e32-4.

2. Tolcher MC, Fisher WE, Clark SL. Nonobstetric surgery during pregnancy. Obstet Gynecol. 2018;132:395-403.

3. Vega J, Videla C, Santis O, Lira M, Goecke H. Kidney transplantation during a twin pregnancy. Case report and review of the literature. CEN Case Rep. 2012;1:43-9.

4. Kim M, Rostas S, Gabardi S. Mycophenolate fetal toxicity and risk evaluation and mitigation strategies. Am J Transplant. 2013;13:1383-9.

5. Hou S. Pregnancy in chronic renal insufficiency and end-stage renal disease. Am J Kidney Dis. 1999;33:235-52.

6. Buckner $\mathrm{CL}$, Wilson L, Papadea CN. An unusual cause of elevated serum total beta hCG. Ann Clin Lab Sci. 2007;37:186-91.

7. De Backer B, Goffin F, Nisolle M, Minon JM. Persistent low hCG levels beyond pregnancy: report of two cases and review of the literature. Ann Biol Clin (Paris). 2013;71:496-502.

8. Fahy BG, Gouzd VA, Atallah JN. Pregnancy tests with end-stage renal disease. J Clin Anesth. 2008;20:609-13.

9. Schwarz A, Post KG, Keller F, Molzahn M. Value of human chorionic gonadotropin measurements in blood as a pregnancy test in women on maintenance hemodialysis. Nephron. 1985:39:341-3.

10. Hubinont C, Doutrelepont JM, Vanherweghem JL, Gervy C, Schwers J. Comparison of human chorionic gonadotropin and pregnancy-specific beta 1-glycoprotein in nonpregnant patients undergoing hemodialysis. Nephron. 1986:43:149-50.

11. Cole LA, Sasaki Y, Muller CY. Normal production of human chorionic gonadotropin in menopause. N Engl J Med. 2007;356:1184-6.

12. Soni S, Menon MC, Bhaskaran M, Jhaveri KD, Molmenti E, Muoio V. Elevated human chorionic gonadotropin levels in patients with chronic kidney disease: case series and review of literature. Indian J Nephrol. 2013;23:424-7.

13. Bree RL, Edwards M, Böhm-Vélez M, Beyler S, Roberts J, Mendelson EB. Transvaginal sonography in the evaluation of normal early pregnancy: correlation with HCG level. Am J Roentgenol. 1989;153:75-9.

14. Vellanki K, Hou S. Menopause in CKD. Am J Kidney Dis. 2018;71:710-9.

15. Harlow SD, Gass M, Hall JE, Lobo R, Maki P, Rebar RW, et al. Executive summary of the stages of reproductive aging workshop +10 : addressing the unfinished agenda of staging reproductive aging. J Clin Endocrinol Metab. 2012;97:1159-68.

16. Sikora-Grabka E, Adamczak M, Kuczera P, Szotowska M, Madej P, Wiecek A Serum anti-Müllerian hormone concentration in young women with chronic kidney disease on hemodialysis, and after successful kidney transplantation. Kidney Blood Press Res. 2016;41:552-60.

17. Stoumpos S, Lees J, Welsh P, Hund M, Geddes CC, Nelson SM, et al. The utility of anti-Müllerian hormone in women with chronic kidney disease, on 
haemodialysis and after kidney transplantation. Reprod BioMed Online. 2018:36:219-26.

18. Sherman BM, West JH, Korenman SG. The menopausal transition: analysis of $\mathrm{LH}, \mathrm{FSH}$, estradiol, and progesterone concentrations during menstrual cycles of older women. J Clin Endocrinol Metab. 1976;42:629-36.

19. Tangren J, Nadel M, Hladunewich MA. Pregnancy and end-stage renal disease. Blood Purif. 2018:45:194-200.

20. Braunstein GD. False-positive serum human chorionic gonadotropin results: causes, characteristics, and recognition. Am J Obstet Gynecol. 2002;187:217-24.

21. Patel KK, Qavi AJ, Hock KG, Gronowski AM. Establishing reference intervals for hCG in postmenopausal women. Clin Biochem. 2017;50:234-7.

22. Liu X. Classification accuracy and cut point selection. Stat Med. 2012;31: 2676-86.

23. Bossuyt PM, Reitsma JB, Bruns DE, Gatsonis CA, Glasziou PP, Irwig L, et al. STARD 2015: an updated list of essential items for reporting diagnostic accuracy studies. BMJ. 2015;351:h5527.

24. Whiting PF, Rutjes AW, Westwood ME, Mallett S, Deeks JJ, Reitsma JB, et al. QUADAS-2: a revised tool for the quality assessment of diagnostic accuracy studies. Ann Intern Med. 2011;155:529-36.

25. Hladunewich MA, Melamad N, Bramham K. Pregnancy across the spectrum of chronic kidney disease. Kidney Int. 2016;89:995-1007.

26. Hou SH. Frequency and outcome of pregnancy in women on dialysis. Am J Kidney Dis. 1994;23:60-3.

27. Piccoli GB, Alrukhaimi M, Liu ZH, Zakharova E, Levin A. Women and kidney disease: reflections on world kidney day 2018. Kidney Int. 2018;93:278-83.

28. Wiles K, Lightstone L. Glomerular disease in women. Kidney Int Rep. 2018;3: 258-70.

29. Webster P, Lightstone L, McKay DB, Josephson MA. Pregnancy in chronic kidney disease and kidney transplantation. Kidney Int. 2017;91:1047-56.

30. Cochrane R, Regan L. Undetected gynaecological disorders in women with renal disease. Hum Reprod. 1997;12:667-70.

31. Holley JL, Schmidt RJ, Bender FH, Dumler F, Schiff M. Gynecologic and reproductive issues in women on dialysis. Am J Kidney Dis. 1997;29:685-90.

32. Kruszynska A, Slowinska-Srzednicka J. Anti-Müllerian hormone (AMH) as a good predictor of time of menopause. Menopause Review-Przeglad Menopauzalny. 2017;16:47-50.

33. Lim VS. Reproductive endocrinology in uraemia. Baillière's Clin Obstet Gynaecol. 1987;1:997-1008

34. Hladunewich MA, Hou S, Odutayo A, Cornelis T, Pierratos A, Goldstein M, et al. Intensive hemodialysis associates with improved pregnancy outcomes: a Canadian and United States cohort comparison. J Am Soc Nephrol. 2014; 25:1103-9.

35. Gill JS, Zalunardo N, Rose C, Tonelli M. The pregnancy rate and live birth rate in kidney transplant recipients. Am J Transplant. 2009;9:1541-9.

36. Deshpande NA, James NT, Kucirka LM, Boyarsky BJ, Garonzik-Wang JM, Montgomery RA, et al. Pregnancy outcomes in kidney transplant recipients: a systematic review and meta-analysis. Am J Transplant. 2011;11:2388-404.

37. Oliverio AL, Bragg-Gresham JL, Admon LK, Wright Nunes JA, Saran R, Heung M. Obstetric deliveries in US women with ESKD: 2002-2015. Am J Kidney Dis. 2020; in press.

38. Shah S, Christianson AL, Meganathan K, Leonard AC, Schauer DP, Thakar CV. Racial differences and factors associated with pregnancy in end stage kidney disease patients on dialysis in the United States. J Am Soc Nephrol. 2020; in press

39. Toth-Manikowski SM, Crews DC. Race, pregnancy, and ESKD. J Am Soc Nephrol. 2019;30:2280-2.

40. Kidney Disease. Improving Global Outcomes (KDIGO) Transplant Work Group. KDIGO Clinical Practice Guideline for the care of kidney transplant recipients. Am J Transplant. 2009;9 Suppl 3:S1-157.

41. Apfelbaum JL, Connis RT, Nickinovich DG, Pasternak LR, Arens JF, Caplan RA, et al. Practice advisory for preanesthesia evaluation: an updated report by the American Society of Anesthesiologists Task Force on Preanesthesia evaluation. Anesthesiology. 2012;116:522-38.

42. Birken S, Maydelman Y, Gawinowicz MA, Pound A, Liu Y, Hartree AS. Isolation and characterization of human pituitary chorionic gonadotropin. Endocrinology. 1996;137:1402-11.

43. Cole LA, Gutierrez JM. Production of human chorionic gonadotropin during the normal menstrual cycle. J Reprod Med. 2009;54:245-50

44. Marks V. False-positive immunoassay results: a multicenter survey of erroneous immunoassay results from assays of 74 analytes in 10 donors from 66 laboratories in seven countries. Clin Chem. 2002;48:2008-16.
45. Wijnsma KL, Duineveld C, Volokhina EB, van den Heuvel LP, van de Kar N, Wetzels JFM. Safety and effectiveness of restrictive eculizumab treatment in atypical haemolytic uremic syndrome. Nephrol Dial Transplant. 2018;33:635-45.

\section{Publisher's Note}

Springer Nature remains neutral with regard to jurisdictional claims in published maps and institutional affiliations.
Ready to submit your research? Choose BMC and benefit from:

- fast, convenient online submission

- thorough peer review by experienced researchers in your field

- rapid publication on acceptance

- support for research data, including large and complex data types

- gold Open Access which fosters wider collaboration and increased citations

- maximum visibility for your research: over $100 \mathrm{M}$ website views per year

At BMC, research is always in progress.

Learn more biomedcentral.com/submissions 